\title{
Perceptions on the Role of Guidance and Counselling Programme on Kenyan Secondary School Students' Career Decision Making
}

Fr Racho Ibrahim

\author{
Catholic University of Eastern Africa, Kenya \\ Dr Peter J.O. Aloka \\ Jaramogi Oginga Odinga University of Science and Technology, Kenya \\ Dr Pascal Wambiya \\ Co-ordinator of Academic Programmes, Catholic University of Eastern Africa, \\ Kenya P.O. BOX 62157, 00200, Nairobi, Kenya \\ Email:pwambiya@cuea.edu \\ Dr Pamela Raburu
}

Jaramogi Oginga Odinga University of Science and Technology, Kenya

\section{Doi:10.5901/jesr.2014.v4n6p313}

\begin{abstract}
The study investigated the Perceptions on the role of guidance and counselling programme on Kenyan secondary school students' career decision making. The study adopted descriptive survey design and the sample size comprised 250 students in the district selected using stratified sampling technique and six guidance and counselling teachers also randomly selected for the study. The researcher used questionnaires and interviews to elicit information from students and interview schedules to collect data from counselling teachers and principals. The results indicated that, there was a significant relationship between role of guidance and counselling for both form one/two $(X 2=1.440, d f=2, P=.001<.05)$ and form three and four $(X 2=3.263, d f=2$, $P=.001<.05)$. It was revealed by the analysis that students agreed that academic, personal and social competence were roles played by guidance and counselling in schools. Similarly, guidance and counselling helped them to attain spiritual growth, vocational, health and marital awareness. Therefore, the implication is that career counselling should be inherently practiced to provide the students with indispensable information and competence required in the world of work.
\end{abstract}

Keywords: Perceptions, guidance, counselling, Kenyan, secondary school, career decision making

\section{Introduction}

Guidance and counselling services have been introduced in Kenyan secondary schools to address several issues. Moreover, a unit was thus established at the Kenyan ministry of education to undertake such services in schools. The Koech Commission (Republic of Kenya, 2009) noted that the guidance and counseling unit in the Ministry provided very effective services to secondary schools as well as being able to conduct in-service courses for primary school head teachers in various districts. In addition, the unit developed a very useful career guidance booklet for use by secondary school students when filling in career application forms. However, the Commission noted with concern (Republic of Kenya, 1999) that the "once vibrant unit" was no longer as effective as it used to be. Since most of the professionally trained personnel in the unit had retired or were deployed to other sections, institutional and field staff had nowhere to seek the necessary advice to help them carry out their duties effectively. The Report (1999) further noted that guidance and counseling remained a very weak component at all levels of the education system and that even where it existed it was undertaken in a haphazard manner. This was because teachers identified for the purpose had not been trained and so had no professional competence in the subject. This situation is common across many public secondary schools in Kenya. The challenges facing guidance and counseling has also been experienced in public secondary schools in Marsabit County especially in Marsabit Central district. Statistics from the District Education Office in Marsabit Central 
indicated that only one out of three public secondary schools had guidance and counseling teachers (Marsabit District Education Office, 2013). Research carried out by the United Nations Educational Scientific and Cultural Organization Programme (UNESCO, 2012) in Marsabit Central District found out that counseling services were not effectively conducted to many students in schools and therefore, they were not ready to make informed career choices. The research by (UNESCO, 2012) further indicated $91 \%$ of teachers in Marsabit concentrated their counseling efforts on averting the negative cultural beliefs affecting students and ignored career counseling. Consequently, not much attention has been devoted to counseling especially in the area of career decision making. As a result many students completing secondary schools have not been able to make correct choices of what careers to pursue (Joint Admissions Board, 2012). This was supported by further inquiry by the Quality Assurance Officers in Marsabit Central district who reported that less than half of the students in the district received career guidance and counseling in form four (Ministry of Education, 2012). Interviews with Ministry of Education (Kenya) officials and career guidance teachers from the district confirmed that students were simply given the careers booklet with university courses, their prerequisite subjects and cutoff points, instead of career guidance and counseling due to limited skilled human and time resources in the area (Ministry of Education, 2012). If this situation is not urgently addressed, the effects may spiral into the job market, leading to lack of professionalism, non-adherence to professional ethics, dissatisfaction in career and low productivity. However, very little scientific inquiries have been made to avert this situation. This scanty literature therefore prompted the researcher take an extensive detour on the role of guidance and counseling in students' career decision-making in public secondary schools of Marsabit Central, Marsabit County, Kenya. A naturalistic study carried out by Norman (2012) in Marsabit East district reported that, out of 100 students counseled $75 \%$ of them did not receive career counseling; leaving the students vulnerable to poor choices after completion of form four (Duda, 2006). In addition, the findings of the study pointed out that girls were mostly affected due to negative cultural beliefs that encouraged them not to pursue careers on equal platform with their male counter parts. However, these studies were neither conducted in Marsabit Central district nor did they assess the role of guidance and counseling on students' career decision-making. Due to poor status of career counseling, this study assessed the role of guidance and counseling in students' career decision making in public secondary schools in Marsabit Central District of Marsabit County, Kenya.

\section{Theoretical Framework and Literature Review}

\subsection{The theoretical framework}

This study was informed by the Super's (2007) theory which is most clearly depicted through the postulation of life roles and life space. Life at any moment is an aggregate of roles that one is assuming, such as child, student, leisurite, citizen, worker, parent, and homemaker. The salience of different life roles changes as one progress through life stages, yet at each single moment, two or three roles might take a more central place, while other roles remain on the peripheral. Life space is the constellation of different life roles that one is playing at a given time in different contexts or cultural "theatres", including home, community, school, and workplace. Role conflicts, role interference, and role confusions would likely happen when individuals are constrained in their ability to cope with the demands associated with their multiple roles. Super was instrumental in developing the international collaborative research work called Work Importance Study (WIS) aiming to study work role salience and work values across different cultures. The WIS involved multiple nations in North America, Europe, Africa, Australia and Asia, and resulted in measures of work roles and work values with similar structure and constructs. This theory has many strengths as many of its aspects are attractive to international career guidance professional and researchers, including concepts such as vocational developmental tasks, developmental stages, career maturity and life roles. It also offers a comprehensive framework to describe and explain the process of vocational development that could guide career interventions and decision-making. The recent anchoring of the theory on developmental contextualism takes into consideration the reciprocal influence between the person and his/her social ecology, including one's culture. Likewise, the conceptualization of career choice and development as a process of personal and career construction recognizes the effects of subjective cultural values and beliefs in shaping vocational self-concepts and preferences. A good portion of the international research studies on Super's theory have used career maturity as one of the major variables (Patton \& Lokan, 2008). Career maturity was examined in two recent qualitative studies conducted in Australia by Patton, Creed, and Muller (2012) administered to Grade 12 students the Australian version of the Career Development Inventory (CDI-A) and a measure of psychological well-being. These students were surveyed on their educational and occupational status 9 months after they graduated. In addition to career maturity, there are other aspects of Super's theory that need to be examined across cultures. For example, self concept 
is a prominent feature of Super's theory, and the implementation of one's interests, values, and skills in a work role is instrumental to vocational development and satisfaction. However, there are cultural variations in the importance of self in decision-making, and in some cultures important life decisions such as career choices are also subjected to considerations that are familial and collective in nature. In order to maximize self-fulfillment and social approval, one has to negotiate with the environment to locate the most acceptable solutions and option (Leung \& Chen, 2007). Consequently, career choice and development is not a linear process of self-concept implementation, but a process of negotiations and compromises in which both the self and one's environment have to be consulted. The concept of life role can also be useful in understanding the cultural dynamics involved the career choice process. Values such as filial piety, family harmony, and loyalty might influence how the personal self is constructed, and the salience and importance of different life and work roles as well as their dynamic interactions.

\subsection{Review of Literature}

Several studies have been carried on the Role of Guidance and Counselling Programme in Decision Making in Schools. For example, Sink and Stroh (2007) completed a large-scale (state-wide) study in Washington DC using a causal comparative design to find out whether school counselling interventions in elementary schools with guidance and counselling programs foster higher academic achievement test scores in students. The study was completed exceptionally well from a measurement perspective and provided excellent support and validation for the hard work that school counsellors did to ensure that students received social, emotional, psychological and academic support from them. The findings reported that early elementary-age students who attend the same school for three or more years do better academically when there is guidance and counselling program, even if it is not fully implemented. Additionally, students who remained in the same school for multiple years with a well-implemented counselling program will obtained higher achievement test scores than students who attend schools without such programs. They recommended full implementation of counselling programs in all the schools. The reviewed study above focused on finding out whether or not guidance and counselling in schools lead to good academic achievements among students. This context was limited and was explored in this study as part of the constructs that underpinned the phenomenon under investigation. Moreover, the reviewed study adopted causal comparative design which involved both experimental and control groups. Consequently, manipulation of extraneous variables due to this methodology may have been inevitable, leading to ambiguity in conclusions and recommendations. The current study addressed this by adopting descriptive survey design in order to describe state of affairs as it is in the phenomenon under investigation.

In another study, Brigman and Campbell (2008) used a quasi-experimental, pre-post test design to evaluate the impact of a school-counselling-led intervention on student academic achievement and school success behaviours. The results of this study indicated a significant difference between treatment and comparison groups on reading and math scores. These results provide very strong support for the conclusion that school counselling interventions that focus on the development of cognitive, social, and self-management skills can result in sizable gains in student academic achievement. The context of the above reviewed study was based on evaluating the impact of a school-counselling-led intervention on student academic achievement and school success behaviours. However, this context was holistically captured in the current study as part of the constructs of the role of guidance and counselling on students' career decision-making. Moreover, the reviewed study adopted quasi-experimental design which may have led to systematic manipulation of variables.

Gerler and Herndon (2008) conducted a study in California to evaluate the effectiveness of a 10-session, multimodal guidance unit called "Succeeding in School," which was designed to improve academic performance. The results of this study demonstrated that students improved their awareness of how to succeed in school after the intervention through guidance and counselling. Grossman (2009) conducted a randomized field trial of the role of guidance and counselling Second Step curriculum with 790, 2nd and 3rd grade students in South Africa. The findings were that observed physically aggressive behaviour decreased significantly in playground and cafeteria settings and that observed neutral/ prosocial behaviour increased significantly in the same settings. Parent and teacher ratings did not change significantly. Despite these modest findings, because this study used a repeated measures design that controlled for many mediating factors and it used reliable and valid instruments to measure outcomes, this reviewed study was powerful evidence of the role of counselling. The outcomes measured in the above reviewed study may not have provided full exploration of students' career decision-making. The current study hence addressed this gap by exploring the role of guidance and counselling on students' career decision-making. Odongo and Njiru (2010) conducted a single site case study in Nyalenda Secondary school in Kisumu, Kenya to establish the role of guidance and counselling in 
students' motivation. In their findings, they reported that counselling programs though not well developed, had the propensity to motivate the girls to set clear social and career objectives after school. They further concluded that as an intervention program, guidance and counselling is supposed to influence an individual's views about his/her role in the world of work and modify the individual's attitude towards work.

Other studies have also been carried out on Students' Perception towards Career Guidance in Schools. Gysbers (2008) conducted a qualitative study of students' view of school counselling interventions at the elementary level in 2 public schools in Kentucky, USA. The study reported that, classroom guidance can improve elementary school students' behaviours and ability to make career decisions but most students did not believe in counsellors' advice which was often based on an individuals' academic performance. He recommended that students should be aware of importance of career counselling before they experience it. Borders and Drury (2008) carried out a qualitative case study in one elementary school in Amsterdam, Netherlands to identify the relationship between students' perception of counsellors' advice on decision-making. The findings reflected that most students had negative perceptions about counsellors on career decision-making. The interviewed students stated that they could not connect their talents to skills and training being acquired in schools. Ojenge and Muchemi (2010) conducted a study in Nairobi County to find out the perception of students towards counselling. They adopted phenomenological design and interviewed 8 girls on their lived experiences with the counsellors. They found out that most girls did not believe in the counsellors for lack of privacy in the counselling rooms. The findings of the study were finally analyzed using content analysis.

Mau, Bilkos and Fouad (2011) conducted an experimental study in Cairo, Egypt to explore how varying career needs could be addressed to help school girls make career decisions. The study concluded that most counsellors were not sensitive to the career need of many students but instead advised them according to their academic performance. This was scenario was inclusive because students had different talents and in addition, academic performance could be improved through effective counselling. They recommended that the unique educational and vocational needs and barriers facing different minority groups also needs to be addressed in counselling programs in order to help them make the right career decisions. Amerikaner and Summerlin (2012) conducted a study in Chicago to find out how students viewed their counsellors and teacher. They conducted a survey on 200 students in $3^{\text {rd }}$ and $4^{\text {th }}$ grades using questionnaires to elicit data. They found out that most counsellors and teachers had no plans to provide leadership in the development, promotion, facilitation and dissemination of school counselling research demonstrating the connection between school counselling programs and student success.

Out of the five studies reviewed to answer the first question in this chapter, three were conducted in the Western countries and adopted different methodologies away from descriptive survey which will be used in the current study. One study was conducted in Africa but adopted a qualitative paradigm. Finally, only one study was conducted in Kenya but took a different context and methodology. For the third question, three international studies were reviewed and all were conducted in different context and methodologies. One regional and one local studies were reviewed under this question but the role of guidance and counselling on students' career decision-making was not addressed.

\section{Research Methodology}

\subsection{Research Design}

The study adopted descriptive survey design. As explained by Weiss (2006), in this design, the researcher did not only embark on fact finding but also formulated important principles of knowledge and solutions to significant problems concerning the phenomenon under investigation. Therefore, quantitative methods which involve systematic and objective collection and analysis of data were adopted in this study to elicit responses from the participants in order to find solutions to the problems identified.

\subsection{Study participants}

The target population of students was 2,259 which is the total number of students' in public secondary school in the district. Furthermore, nine guidance and counselling teachers were also targeted for the study because they provided counselling services to the affected students. Out of nine public secondary schools in the district, 6 schools representing $67 \%$ were selected using simple random sampling method. This sampling technique was used because it ensured that the "unknown" influences were equally distributed within the sample (Lincoln \& Guba, 2007). Therefore, 250 students representing $11.1 \%$ of the total 2,259 in the district were selected using stratified sampling technique. Six guidance and 
counselling teachers representing $67 \%$ of the 9 guidance and counselling teachers in the district were also randomly selected for the study.

\subsection{Research Instruments}

The researcher used questionnaires and interviews to elicit information from students and interview schedules to collect data from counseling teachers and principals. Questionnaires were used to acquire the necessary quantitative data from the students. It sought information on the role of guidance and counselling programme in the selected schools and students', counsellors and teachers perceptions in career decision-making. To ensure validity of the questionnaires, the questionnaires were amended after the supervisors' advice as preferred by Frankfort-Nachmias and Nachmias (2006). The content validation was therefore appropriate in determining the extent to which the set of items provided relevant and representative sample of the domain of tasks under consideration (Gronlund, 2005). In this study, the reliability coefficient of the items (on the Likert Scale) in the students' questionnaire was computed to yield figures above 0.6 and considered reliable (Cronbach, 2005).the researcher ensured dependability of interview data by the research design and its implementation; describing what was planned and executed on a strategic level, the operational detail of data gathering; addressing the minutiae of what was done in the field and reflective appraisal of the project; evaluating the effectiveness of the process of inquiry to be undertaken.

\subsection{Data collection procedures}

The researcher sought permission from the Catholic University of Eastern Africa, the National Commission for Science, Technology and Innovation, Marsabit County and District Education Officer in Marsabit Central to conduct the study. When the permission was granted, the researcher made an official application through writing to the schools through their principals to be allowed to use the institutions for the study and categorically stated the purpose of the study and the target respondents. After being granted permission by the authorities of various institutions, the researcher visited the schools, read and issued informed consent forms to the selected participants. The participants were then signed the consent form and return it to the researcher agreeing to voluntarily participate in the study. The researcher then distributed questionnaires to the selected students who consented to participate in the study by help of guidance and counselling teachers in the selected schools. All clarifications were made to all the students and date and place of collection of questionnaires agreed upon.

Interview for each participant took between 35-45 minutes.

\subsection{Data analysis}

Data from the questionnaire was quantitatively analyzed in order to identify general trends in the selected population (Gall \& Borg, 2006). Then, the coded data was analyzed by use of computer software; the Statistical Package for Social Sciences (SPSS) version 22 with various tests. The analysis of quantitative data included descriptive, inferential and nonparametric statistics. For qualitative data, the researcher employed De Vos and Fouché (2008) eight steps approaches to data analysis. These included, reading through all excerpts carefully to get a sense of the whole; selecting one participant's response to find underlying meanings and thoughts of the responses which were then written in the margin; the step had to be repeated for all participants in the study; clustering similar topics together; matching the list to the data and finding out emerging categories; reducing categories by grouping related topics that showed interrelationships; each category was coded and arranged accordingly; assembling data material belonging together into one place and beginning with preliminary analysis; finally, existing data was recorded where necessary.

\section{Findings and Discussion}

\subsection{Findings based on the role of guidance and counselling programme on students' career decision making}

The first research question sought to establish the role of guidance and counselling programme on students' career decision-making in public secondary schools in Marsabit central district. As such, a five-point Likert scale with 18 items denoting role of guidance and counselling was used to achieve this. The scale was rated as follows: Strongly agree=5, Agree $=4$, Undecided $=3$, Disagree $=2$ and Strongly disagree $=1$. The measure of linearity of this scale revealed a Median 
(cut-point) of 3. Therefore, any mean score less than 3 denoted that the majority of the respondents disagree with the items as being roles of guidance and counselling. Further, any mean score greater than 3 denoted that the majority of the respondents agreed that the items were roles of guidance and counselling. This is presented in table 1.

Table 1: Descriptive Statistics on the Role of Guidance and Counselling.

\begin{tabular}{lcc}
\hline Role of Guidance and Counselling & Mean & Std. Deviation \\
\hline Academic competence & 4.78 & .441 \\
Personal competence & 4.67 & .500 \\
Social competence & 4.22 & .667 \\
Spiritual growth & 4.44 & 1.333 \\
Vocational awareness & 4.33 & 1.000 \\
Marital awareness & 4.44 & .527 \\
Health awareness & 5.00 & .000 \\
Understand self & 4.89 & .333 \\
Solve my problems & 4.44 & .726 \\
High self esteem & 4.56 & 1.014 \\
Positive self concept & 4.56 & .527 \\
Good personality & 5.00 & .000 \\
Good morals & 4.56 & .726 \\
Peer respect & 4.67 & .500 \\
Discipline & 4.44 & 1.333 \\
Reduce anxiety & 4.11 & .782 \\
Parental acceptance & 4.22 & .972 \\
Good study habits & 4.56 & 1.014 \\
\hline
\end{tabular}

The information on Table 1 revealed that the mean scores on the role of guidance and counselling ranged from 4.11 to 5.00. Both values were above the cut-point (3.00) indicating that the majority of respondents agreed that the items denoted roles played by guidance and counselling programme. The difference between the highest and the lowest means was 0.89 indicating there were few outliers in the data. Thus, the items were relevant to the roles of guidance and counselling. Further, to ascertain how varied (close or far) the responses were placed in relation to the mean score, standard deviation was calculated and revealed a minimum value of .000 and a maximum value of 1.333 . In general, this indicated that the respondents closely (strongly) agreed that the items denoted roles of guidance and counselling (S.D, .000; Mean, 5.00) in secondary schools in Marsabit central district, Kenya. In general, guidance and counselling played a role in instilling students' personal competence $(4.67, .500)$, social competence $(4.22, .667)$ spiritual growth $(4.44,1.333)$ vocational awareness $(4.33,1.000)$ and marital awareness $(4.44, .527)$. It also helped them in solving problems $(4.44$, $.726)$, imparted high self esteem $(4.56,1.014)$, positive self-concept $(4.56, .527)$, good morals $(4.56, .726)$, peer respect $(4.67, .500)$, discipline $(4.44,1.333)$, parental acceptance $(4.22, .972)$ and improved their study habits $(4.56,1.014)$. All the mean scores were greater than 3 indicating further implying that the items were roles of guidance and counselling, these findings are similar to findings by Brigman and Campbell (2008) used a quasi-experimental, pre-post test design to evaluate the impact of a school-counselling-led intervention on student academic achievement and school success behaviours.

Because of mean differences, the analysis revealed the lowest mean score of 4.11 yielding standard deviation of .782 for "reduce anxiety". This implied that although all the items were agreed upon as roles of guidance and counselling, reduction of anxiety among students was the least role of guidance and counselling programme in secondary schools of Marsabit central district. However, to establish the mean differences within the variables tested, the researcher ran Tests of homogeneity of variance for all categories using Levene's test of homogeneity of variance. This test revealed that there was homogeneity of variance among the variables. This implied that there was no significant difference between the variance noted and guidance and counselling programme ( $p>0.05)$.

A correlation analysis between guidance and counselling and career decision-making revealed a significant and positive relationship $(r=.469, p=.000)$. This showed that effective guidance and counselling programme had a positive influence on students' career decision-making. These findings were similar to those found by Sink and Stroh (2007) who completed a large-scale (state-wide) study in Washington DC using a causal comparative design to find out whether school counselling interventions in elementary schools with guidance and counselling programs foster higher academic achievement test scores in students. They reported that guidance and counselling program fostered academic 
achievements.

There was need to employ non-parametric test to compare observed data with data the researcher would expect to obtain. The Chi-square was thus calculated because the expected values in all categories were more than 5 . Responses from the Likert scale were cross-tabulated with the class levels to compute the number of students, total, ratio and Chi-square $\left(x^{2}\right)$ value. Values less than the critical value 0.05 were considered significant for the variables. The results are presented in table 2 .

Table 2: Chi-square test results for role of guidance and counselling programme

\begin{tabular}{|c|c|c|c|c|c|c|c|c|c|}
\hline Class level & Role of guidance and counselling & & & & & & & & Chi-square test $\left(\mathrm{x}^{2}\right)$ \\
\hline \multirow{19}{*}{$\begin{array}{c}\text { Form one and two } \\
\text { students }\end{array}$} & & SA & A & $U$ & D & SD & Total & Ratio & $X^{2}=1.440$ \\
\hline & Academic competence & 30 & 10 & 0 & 0 & 0 & 40 & .032 & $\mathrm{df}=2$ \\
\hline & Personal competence & 20 & 20 & 0 & 0 & 0 & 40 & .908 & $P=.001^{*}$ \\
\hline & Social competence & 10 & 20 & 0 & 10 & 0 & 40 & 1.816 & \\
\hline & Spiritual growth & 30 & 0 & 0 & 0 & 10 & 40 & 2.805 & \\
\hline & Vocational awareness & 20 & 10 & 0 & 0 & 10 & 40 & 1.816 & \\
\hline & Marital awareness & 20 & 20 & 0 & 0 & 0 & 40 & .090 & \\
\hline & Health awareness & 40 & 0 & 0 & 0 & 0 & 40 & - & \\
\hline & Understand myself & 30 & 10 & 0 & 0 & 0 & 40 & 1.780 & \\
\hline & Solve my problems & 20 & 10 & 0 & 0 & 10 & 40 & 1.816 & \\
\hline & High self-esteem & 30 & 0 & 0 & 10 & 0 & 40 & 2.805 & \\
\hline & Positive self-concept & 10 & 30 & 0 & 0 & 0 & 40 & 2.863 & \\
\hline & Good personality & 40 & 0 & 0 & 0 & 0 & 40 & - & \\
\hline & Good morals & 30 & 10 & 0 & 0 & 0 & 40 & 1.275 & \\
\hline & Peer respect & 30 & 10 & 0 & 0 & 0 & 40 & .228 & \\
\hline & Discipline & 30 & 0 & 0 & 0 & 10 & 40 & 2.805 & \\
\hline & Reduce anxiety & 10 & 10 & 20 & 0 & 0 & 40 & 4.048 & \\
\hline & Parental acceptance & 10 & 20 & 10 & 10 & 0 & 40 & 2.325 & \\
\hline & Improves study habits & 20 & 10 & 0 & 10 & 0 & 40 & 3.990 & \\
\hline \multirow[t]{7}{*}{ Class level } & Role of guidance and counseling & & & & & & & & Chi-square test $\left(\mathrm{x}^{2}\right)$ \\
\hline & & SA & A & $\mathrm{U}$ & D & SD & Total & Ratio & $X^{2}=3.263$ \\
\hline & Academic competence & 40 & 10 & 0 & 0 & 0 & 50 & .032 & $d f=2$ \\
\hline & Personal competence & 40 & 10 & 0 & 0 & 0 & 50 & .908 & $P=.001^{*}$ \\
\hline & Social competence & 20 & 20 & 10 & 0 & 0 & 50 & - & \\
\hline & Spiritual growth & 40 & 10 & 0 & 0 & 0 & 50 & 1.275 & \\
\hline & Vocational awareness & 20 & 30 & 0 & 0 & 0 & 50 & 2.375 & \\
\hline \multirow{13}{*}{$\begin{array}{c}\text { Form three and four } \\
\text { students }\end{array}$} & Marital awareness & 20 & 30 & 0 & 0 & 0 & 50 & 1.801 & \\
\hline & Health awareness & 50 & 0 & 0 & 0 & 0 & 50 & 1.816 & \\
\hline & Understand myself & 50 & 0 & 0 & 0 & 0 & 50 & 2.805 & \\
\hline & Solve my problems & 30 & 20 & 0 & 0 & 0 & 50 & .228 & \\
\hline & High self-esteem & 40 & 10 & 0 & 0 & 0 & 50 & 4.048 & \\
\hline & Positive self-concept & 40 & 10 & 0 & 0 & 0 & 50 & - & \\
\hline & Good personality & 50 & 0 & 0 & 0 & 0 & 50 & - & \\
\hline & Good morals & 30 & 10 & 10 & 0 & 0 & 50 & 2.308 & \\
\hline & Peer respect & 30 & 20 & 0 & 0 & 0 & 50 & .785 & \\
\hline & Discipline & 40 & 10 & 0 & 0 & 0 & 50 & .325 & \\
\hline & Reduce anxiety & 20 & 30 & 0 & 0 & 0 & 50 & .907 & \\
\hline & Parental acceptance & 30 & 20 & 0 & 0 & 0 & 50 & 1.804 & \\
\hline & Improves study habits & 50 & 0 & 0 & 0 & 0 & 50 & 2.805 & \\
\hline
\end{tabular}

*Significant at $p<0.05$ level

The results obtained in Table 2 indicated that, there was a significant relationship between role of guidance and counselling for both form one/two $\left(X^{2}=1.440, \mathrm{df}=2, P=.001<.05\right)$ and form three and four $\left(X^{2}=3.263, \mathrm{df}=2, P=.001<.05\right)$. It was revealed by the analysis that students at all class levels agreed that academic, personal and social competence were roles played by guidance and counselling in schools. Similarly, it was also revealed that guidance and counselling helped them to attain spiritual growth, vocational, health and marital awareness. All the other constructs tested as roles of guidance and counselling had statistical significance. The findings are similar to Grossman's (2009) who conducted a 
randomized field trial of the role of guidance and counselling Second Step curriculum and reported that guidance and counselling had a great significance in $2^{\text {nd }}$ and $3^{\text {rd }}$ grade students. He reported that these concepts were roles of guidance and counselling.

Interviews were also carried out on the role being played by general guidance and counselling in schools. The teacher counsellors were asked their role as a counsellor and she narrated several areas and ways in which counselling plays requisite roles. One of these roles was to provide requisite guidance to students in their areas of need. She plausibly talked about gifted and average students because their needs are not the same.

Some gifted students appear to be more mature than their chronological age indicates. They have advanced skills and can make decisions that may not seem to be in line with their talents or academic ability. Nevertheless, they are still adolescents and need realistic, clearly stated guidelines about limits, values, and proper behaviour. These young girls and boys may not have enough information or experience to make wise and effective decisions. They may not understand decision-making processes, and they need wise adults like teachers or parents to listen and guide as they talk through their career decisions, the alternatives, and the pro's and con's and try out choices. Knowing that they can be independent and still talk through their thoughts with others without losing face reduces stress for these students. These students need to hear adults openly state some of their perspectives to understand expectations and acceptable limits. While these students are very perceptive, they cannot read minds. Even average students may know more facts about their interest area than do their parents and other adults. However, they have not lived longer; they need loving concern and guidance to help them make the right decisions and this is where counselling comes in. [Teacher counsellor 4].

This means that counselling should be offered in such a way that every individual character is taken in to consideration. The above findings corroborate those of Odongo and Njiru (2010) who found out that guidance and counselling played the role of students' motivation. This indicates that guidance and counselling is multifunctional and addresses many areas and needs of secondary school students. As such, its implementation and evaluation by professionals should be made a priority in all schools including those in marginalized areas of the country like Marsabit East district, Marsabit County.

Further inquiry through the school counsellor revealed interesting findings on role of guidance and counselling, helps in sustaining positive influence on students' career and academic performance, includes acquiring skills, attitudes and knowledge that contribute to effective learning in school; employing strategies to achieve success in school; and understanding the relationship of academics to the world of work, and to life at home and in the community. Academic goals support the premise that all students should meet or exceed the local and national learning goals. Similarly, career development goals guide the school counselling program to provide the foundation for the acquisition of skills, attitudes and knowledge that enable students to make a successful transition from school to the world of work and from job to job across the life span. Career development goals and competencies ensure that students develop career goals as a result of their participation in a comprehensive plan of career awareness, exploration and preparation activities. One teacher counsellor asserted:

Students will acquire the attitudes, knowledge and skills that contribute to effective learning in school and across the life span. Students will complete school with the academic preparation essential to choose from a wide range of substantial post secondary options, including college. Students will understand the relationship of academics to the world of work and to life at home and in the community [Teacher counsellor 1].

These findings meant that apart from normal teaching and learning program in schools, guidance and counselling play important role in shaping their academic plans. In addition, these findings are similar to those revealed by Grossman (2009) who found out that effective counselling programme enables the students to apply knowledge during and after school in South Africa. Therefore, the implication is that career counselling should be inherently practiced to provide the students with indispensable information and competence required in the world of work. This indicates the general importance in the role of guidance and counselling among students around the world.

The findings are similar to the results of a study carried out by Gerler and Herndon (2008) who reported that guidance and counseling helped students to cope with academic, social and other cognitive issues affecting them in and outside school.

Through the interviews, it was also revealed that, effective guidance and counseling inspired students to engage in meaningful social, emotional leisure and learning activities. This was reported by one of the participants:

At a time when friendships and social interaction are particularly important for young adolescents, the normative transition into high school often serves to disrupt friendship networks and, thereby, interferes with students' success in high school. Thus, it is vital for a transition program to include activities that will provide incoming students social support 
activities that give students the opportunity to get to know and develop positive relationships with older students and other incoming students. We have a big sister/brother program that begins in form one and continues through form three, a termly social event for current and incoming high school students, and writing programs where form ones correspond with high school students are just a few ways that transition programs can provide students social support. Counselors also look for opportunities to develop more long-term activities such as peer mentoring or tutoring programs. All this provide social support and give the students the right environment to make right decisions [Teacher counselor 2].

These findings mean that schools should have effective transition activities as they come to high schools. This will give them conducive environment to be able to cope well in school and these activities are organized by counseling departments. The findings imply that students could make right and informed career decisions once accorded the right environment. This is similar to the findings by another study by Brigman and Campbell (2008) who reported that impact of a school-counselling-led intervention on student academic achievement and school success behaviours helped them to be better in their social and academic life.

These findings imply that teacher counsellor plays an important role in enhancing students' capability to make right career decisions. As such career counselling should be given equal attention as academic performance and counselling on social and behavioural issues.

The school principal corroborated these responses by stating that:

There has been remarkable improvement in students' behaviour and decision making due to counselling. The students have also started changing subjects of their choices to suit their passion and academic capabilities [Principal 2].

This implies that, guidance and counselling played a vital role of informing the students on the best way to behave and also to choose subjects based on passion and academic capabilities. This is likely to result to students making the right career decisions. These findings are similar to those revealed by a study carried out by Odongo and Njiru (2010) who found out that effective counselling enabled students to be more productive and approach their academic work with confidence. The implication of this finding is that, counselling services should be effective and reach all students especially on career issues.

\subsection{Findings based on the students' perceptions towards career guidance.}

The study sought to find out the perception of the role of guidance and counselling in career decision making among secondary school students. Here, the perception of guidance and counselling questionnaire was designed with a five point Likert Scale having 20 items. The descriptive statistics results are presented in Table 3.

Table 3: Descriptive Statistics on the Perceptions towards Career Guidance in Public secondary schools.

\begin{tabular}{lcc}
\hline Perception towards career guidance & Mean & Std. Deviation \\
\hline Assist individuals in dealing with career issues & 4.56 & .726 \\
Helps students to access career information & 4.56 & .726 \\
Helps students in making choices based on aspirations & 4.22 & .972 \\
Career guidance department invites speakers on various career issues & 4.33 & .707 \\
Career tests help in getting differences, personalities, interests and values & 4.33 & .866 \\
Helps students in job placement & 4.22 & .667 \\
All students should consult counsellor when making career decisions & 4.56 & .726 \\
Helps make positive difference in one's career life & 4.22 & .667 \\
Career guidance helps students in education planning & 4.33 & .866 \\
I would advice all students with career issues to consult school counsellor & 4.44 & 1.014 \\
Reduces career anxiety & 4.63 & .744 \\
Provides people with information where they can get jobs & 4.00 & 1.069 \\
Career guidance makes students work hard & 3.56 & 1.424 \\
Helps students achieve their academic goals & 3.22 & 1.394 \\
Gives people a list of careers & 3.89 & 1.054 \\
Career guidance does not motivate me & 3.78 & 1.481 \\
My friends are not interested in career guidance & 3.56 & 1.424 \\
Helped people to get right careers & 3.89 & .928
\end{tabular}

The results presented in Table 3 showed that, the mean scores ranged from 3.24 to 4.63 . The highest mean score concerning the perception towards career guidance was that it reduces anxiety (4.63), all students should consult counsellor when making career decisions (4.56), assist individuals in dealing with career issues (4.56), helps students to 
access career information (4.56), I would advice all students with career issues to consult school counselor (4.44), career guidance department invites speakers on various career issues (4.33), career tests help in getting differences, personalities, interests and values (4.33), career guidance helps students in education planning (4.33), helps students in making choices based on aspirations (4.22), helps students in job placement (4.22), helps make positive difference in one's career life (4.22), provides people with information where they can get jobs (4.00), helped people to get right careers (3.89), gives people a list of careers (3.89), career guidance does not motivate me (3.78), career guidance makes students work hard (3.56) and helps students achieve their academic goals (3.22). All the mean scores were above 3 implying that the majority of the students agreed that the items matched their perception of career guidance. This is similar to the findings by Gysbers (2008) who found out that student and parents had positive perception concerning counseling interventions at the elementary level.

However, the findings are contrary to those by Borders and Drury (2008) who reported that parents were not receptive about counseling programs at elementary level since most students were mainly influenced by what they knew concerning certain careers. The implication of this finding is that parents may want to influence career decisions at certain levels and can choose to ignore the importance of career counseling provided in schools.

\subsubsection{One Sample T-test Results on the perceptions towards career guidance}

Here, the desired percentage was $40 \%$ thus the test value was computed at .4. One sample t-test was calculated to establish the difference between class level and students' perceptions towards career guidance. This is because as students progress to higher class levels, their perceptions towards career guidance is more likely to change. The mean value of the distribution was therefore calculated using one sample t-test. The results are presented in table 4.

Table 4: One sample t-test results on perception towards career guidance

\begin{tabular}{ccccccc}
\hline & \multicolumn{5}{c}{ Test Value $=.5$} \\
\cline { 2 - 6 } & & \multirow{2}{*}{ df } & Sig. (2-tailed) & Mean Difference & \multicolumn{2}{c}{ 95\% Confidence Interval of the Difference } \\
\cline { 4 - 6 } Perception of career guidance & 31.418 & 8 & .000 & 72.933 & Lower & Upper \\
\hline
\end{tabular}

The analysis in table 4 revealed that, one sample $t$-test statistic was 31.418 and the $p$-value from this statistic was $.000<.05$ (the level of significance usually used for the test). This $p$-value indicated that the average perception of the sampled students in relation to class level was statistically significantly different from the test value of $50 \%$. The $95 \%$ confidence interval estimated for the difference between the students' mean perception and class level was (67.58 and 78.29). This implied that as students moved to upper class levels, they developed a more positive perception towards career guidance. The findings are similar to Gysbers (2008) who reported that students' positive perception on career guidance empowered them to make right decisions. The implication is that counselling should influence students positively so that they can use its impact to make right career choices.

\section{Concluding Remarks}

The study investigated the perceptions on the role of guidance and counselling programme on Kenyan secondary school students' career decision making. guidance and counselling played a role in instilling students' personal competence, social competence, spiritual growth, vocational and marital awareness. Guidance and counselling also helped students in solving problems, imparting high self esteem, positive self-concept, good morals, peer respect, discipline, parental acceptance and improved their study habits. The analysis on role of guidance and counselling revealed that the students scored the highest mean indicating that all the students supported development of good personality and health awareness as roles played by guidance and counselling in secondary schools. This was followed by the students' agreement though with little variation that guidance and counselling played a role in helping them to better understand themselves. Academic competence was also identified (agreed on) by the students as another strong role of guidance and counselling. Analysis of the perceptions towards career counselling revealed positive perceptions. The highest agreement concerning the perception towards career guidance was that it reduces anxiety; all students should consult counsellor when making career decisions, assist individuals in dealing with career issues, helps students to access career information, I would advice all students with career issues to consult school counsellor, career guidance 
department invites speakers on various career issues, career tests help in getting differences, personalities, interests and values, career guidance helps students in education planning, helps students in making choices based on aspirations, helps students in job placement, helps make positive difference in one's career life, provides people with information where they can get jobs, helped people to get right careers, gives people a list of careers, career guidance does not motivate me, career guidance makes students work hard and helps students achieve their academic goals.

The study recommends that school counsellors should provide a systematic approach to helping all students with the decision making process, to understand; themselves and to develop appropriate goals through the interpretation of standardized test results and course performance. Moreover, the schools' administrations should have a standard format in place to document and review each student's individual planning portfolio on an annual basis. They should also ensure that individual student planning has a specific time for delivery to all students at each class level on an annual basis. Professional school counsellors should incorporate organizational processes and tools that are concrete, clearly delineated and reflective of the school's needs given that Marsabit County is marginalized area with unique needs.

Based on the study findings, the following areas have been suggested for further research. For example, A study can be conducted to determine the effect of career counselling on students' academic performance. Another longitudinal study to investigate the influence of career counselling on students in marginalized areas in Kenya.

\section{References}

Duda, F. (2006). Guidance and counseling. A case study of Machakos Municipality. Unpublished PGDE Thesis, Nairobi: Kenyatta University.

Norman, P. (2012). "Cultural beliefs and counseling among girls in Marsabit East." Journal of Counseling, 2, 61-73.

Super, D. W. (2007). "Vocational development theory." The Counseling Psychologist, 1, 2-30.

Super, D. W. (2007). "A life-span, life-space approach to career development." Journal of Vocational Behavior, 16, 282-298.

Patton, W., \& Lokan, J. (2008). "Perspectives on Donald Super's construct of career maturity." International Journal for Educational and Vocational Guidance, 1, 31-48.

Leung, S. A., \& Chen, P. W. (2007). Developing counseling psychology in Chinese communities in Asia: Indigenous, multicultural, and cross-cultural considerations. Manuscript submitted for publication at Hangzhou Research Center.

Sink, C. A., \& Stroh, H. R. (2007). "Raising achievement test scores of early elementary school students through comprehensive school counseling programs." Professional School Counseling, 6(5), 350-365.

Gerler, E. R., \& Herndon, E.Y. (2008). "Learning how to succeed academically in middle school." Elementary School Guidance and Counseling, 27(3), 186-197.

Grossman, D. C. (2009). "Effectiveness of a violence prevention curriculum among children in elementary school." Journal of the American Medical Association, 227(20), 1605-1611.

Odongo, M. \& Njiru, L. (2010). Motivating the Girl child through Counseling. Kisumu: JKF

Gysbers, N. C. \& Henderson, P. (2008). Developing and managing your school guidance program. (3rd ed.). Alexandria, VA: American School Counseling Association.

Borders, D. L., \& Drury, S. M. (2008). "Comprehensive school counseling programs: A review for policymakers and practitioners." Journal of Counseling and Development, 70, 487-498.

Ojenge, K. \& Muchemi, S. (2010). Students' Perceptions of Counseling programs. Nairobi; New Kemit.

Mau, W., Bilkos, R., \& Fouad, C. (2011). "High school students' career plans: The influence of others' expectations." Professional School Counseling, 2(2), 161-166.

Amerikaner, M., \& Summerlin, M. L. (2012). "Group counseling with learning disabled children: Effects of social skills and relaxation training on self-concept and classroom behavior." Journal of Learning Disabilities, 15(6), 340-343.

Weiss, S.E. (2006). "Associations between the Second to Fourth Digit Ratio and Career Interests." Journal of Personality and Individual Differences, 43, 485-493.

Lincoln, Y. S., \& Guba, E. G. (2007). "Criteria for assessing the trustworthiness of naturalistic Inquiries." Educational Communication and Technology Journal, 29, 75-91.

Frankfort-Nachmias, C. \& Nachmias, D. (2006). Research Methods in Social Sciences (5 $5^{\text {th }}$ Ed) New York: Replika Press Pvt. Ltd.

Gronlund, N. E. (2005). Assessment of Students Achievement. Michigan: Allyn and Bacon.

Cronbach, L. J. (2005). "Test 'reliability': Its meaning and determination." Psychometrika, 12, 1-16.

De Vos \& Fouché, L. (2008). Eight Steps Approaches to Data Analysis. New York: Newbury Park.

Gall, M.D, Borg, W.R. \& Gall, J.P. (2006). Educational Research. An introduction. New York: Longman Publishers.

Sink, C. A., \& Stroh, H. R. (2007). "Raising achievement test scores of early elementary school students through comprehensive school counseling programs." Professional School Counseling, 6(5), 350-365. 
ISSN 2239-978X

ISSN 2240-0524
Journal of Educational and Social Research MCSER Publishing, Rome-Italy
Vol. 4 No. 6 September 2014 